\title{
Public Libraries - Learning and Cultural Transfer Ecosystems. Case study: Cultural Agora@Your Library
}

\author{
Ioana Crihana \\ Executive Director \\ National Association of Public Librarians and Libraries in Romania (ANBPR) \\ E-mail ioanacrihana@yahoo.com
}

Humankind Libraries - as territories of collective experiences - can serve as an infrastructure for testing and validating the new learning paradigms, while being, at the same time, the outposts for initiating different categories of target-groups by mentoring and coaching. Moreover, libraries have the potential to become vibrant spaces for broadcasting and for calibrating new relationship models next to best practices in innovation sprouting, in close connection with everyday life.

Via the Cultural Agora @ Your Library project, the National Association of Public Librarians and Libraries in Romania (ANBPR) has tested a set of modern technology-based tools and techniques whereby library users belonging to different ethnic communities became original digital storytellers on cultural diversity, with the aim of encouraging intercultural dialogue and of preserving multicultural values. ANBPR supports public libraries to become leaders in information navigation, by promoting the library as a dynamic space that inspires the discovery and the connecting of people from different cultures. The library provides always a lot of information, but it rarely provides creations of its own users.

Keywords: library projects; library associations; digital storytelling; cultural dialogue; cultural diversity; minorities

An inspiring experience of National Association of Public Librarians and Libraries in Romania in the cultural diversity field, with the involvement of public librarians and representatives of ethnic minorities

\section{Introduction}

The current society is based on increasingly refined methods of approaching knowledge and collaboration. We are at the core of deep resettlements generated by the phenomenon of migration and the multicultural interactions derived from this ethnic affluence that brings together people and professionals with very diverse cultural backgrounds. In Romania and in Norway alike, there is increasing interest in stimulating multiculturalism and the transfer of know-how among different ethnic communities. This integrative approach has made libraries be considered as collective spaces for testing and validating innovative content co-creation solutions, in the spirit of fostering cultural diversity and preserving the immaterial patrimony of ethnicities.

The National Association of Public Librarians and Libraries in Romania (ANBPR) wanted to capitalize on the experience of using digital stories, by turning the library into an aggregator of collective consciousness and multiculturalism. In this way, ANBPR proposes a new vision for managing cultural knowledge and the experience of public libraries, by proposing a transition from the library as provider of materials, to the library as a facilitator of materials produced by its users.

In 2014, the Cultural Agora@ Your Library project opened for ANBPR an unexplored territory that of valorizing the cultural diversity of minorities, with the participation of public libraries. Starting from a daring and creative idea, the Cultural Agora has crystallized, in a 20-month

Revista Română de Biblioteconomie şi Ştiința Informării = Romanian Journal of Library and Information Science ISSN 2559-5490, ISSN-L 1841-1940 • Volume 14 Issue 12018 pp. 30-34 https://doi.org/10.26660/rrbsi.2018.14.1.30

This work is licensed under a Creative Commons Attribution-NonCommercial-NoDerivatives 4.0 International License 
project-driven scenario, an innovative proposal to turn library service users into co-authors of collective memory by using the technique of digital stories.

The objective of this intervention is to promote the example of Romania-Norway collaboration in the field of creating original user content, using the public libraries infrastructure in Romania and Norway. The role of libraries as facilitators and multipliers of community-based good practice is becoming increasingly pronounced today. ANBPR-New Amigos collaboration creates the premises for new experiments in the field of multiculturalism, encouraging users from different ethnic communities to interact and create content themselves and introduce them to the general audience, to increase inclusion and quality of life through cultural education.

\section{Cultural Agora@Your Library project}

This project is built on a partnership between Romania and Norway, in a consortium of the National Association of Public Librarians and Libraries in Romania - ANBPR, REPLIKA Cultural Association and Jazzmontor AS Norway - an organization specialized in training and consultancy in digital stories field. The Cultural Agora project aimed at promoting cultural diversity, preserving the unchanged values of minorities, cultivating interethnic dialogue and stimulating collaboration between librarians and users, with the support of technology. This project was funded in the context of EEA Grants 2009-2014 PA17 / RO13 Promoting diversity in culture and art within the European cultural heritage.

One of the most fascinating processes of implementing such a project consisted in the manner in which initial ideas were propagated and reconfigured, i.e. by using them in different contexts, with the intervention of the several characters and personalities who put their fingerprint on implementing the project's creative scenario. Cultural Agora was more than merely a cultural experiment, it was an initiatory journey based on anticipation, collaboration, solidarity, but also on unpredictability, specific to dynamic projects, which re-invent themselves by every stage.

The Cultural Agora promise consisted in bringing to the attention of the public at large the heritage value of memory and collective consciousness, as well as in stimulating profane users to contribute to preserving the cultural values of different ethnic minorities. Via digital stories made during the Cultural Agora project, public libraries have become bridges between minorities and the rest of the community.

By the Cultural Agora project, rolled-out between January 2015 and August 2016, ANBPR has taken major steps in transforming public libraries into dynamic, vibrant spaces that encourage experimental discovery and the connecting of people to culture and art with the support of technology. Traditionally, the library is the space where knowledge, information, cultural landmarks, stories and experiences from very different sources are gathered and interfere. The public library offers a multitude of resources and information, but it rarely brings to the audience's attention original stories produced by its own users.

Over time, there have been several isolated initiatives to capture the stories and life experiences of users by using Digital Storytelling in Romanian libraries. But they were just local projects addressing a very limited segment of the audience, usually in a geographically well-defined space. However, ANBPR dared promote the use of digital stories via an innovative approach whereby the library becomes from a resource manager, a genuine facilitator for creating original usergenerated content.

Thanks to Cultural Agora, users from 4 counties (Cluj, Sibiu, Braila and Bucharest) had the opportunity to produce and share their own stories, videos, texts, photos and to make known their own ethnic values and beliefs. Thus, libraries involved in the project - "Octavian Goga" County Library Cluj, "ASTRA" County Library Sibiu, "Panait Istrati" County Library Brăila and 
Metropolitan Library of Bucharest - have turned into spaces of interethnic dialogue where digital stories have become innovative ways of preserving the unwritten history of ethnic communities and facilitating the exchange of knowledge and experience among library users.

The use of the Digital Storytelling method calls for artistic and creative skills as well as technical competences, a good knowledge of copyright issues, computer applications and audio-video editing processes. Participating in the Digital Storytelling training sessions within the Cultural Agora project was free of charge, based on enrollment, engaging people with different ethnicities, religious beliefs and especially with very different ages and professions. Via the complexity of the creative approach and the generous theme of the digital stories, the Cultural Agora project has provided extensive research on the cultural diversity of the 4 counties involved.

\section{Results}

In terms of project outcomes, in the context of the Cultural Agora project, the participants created over 1,500 digital stories of which more than 190 stories about the Roma culture, with the participation of more than 1,500 participants, including more than 500 ethnic participants, of which 230 Roma participants and more than 170 librarians.

The Cultural Agora project supported 4 libraries in Bucharest, Cluj, Sibiu and Braila to become community centers for digital stories. Relying on the free-of-charge workshops facilitated by librarian-trainers during the 20-month project, more than 1,500 library-services users involved in Digital Storytelling sessions have produced more than 1,500 original digital stories.

Moreover, the project supported the participation of members from various local ethnic communities (Hungarians, Germans, Turks, Tartars, Hebrew, Roma etc.). Based on the digital stories produced and collected, the 4 libraries organized temporary exhibitions of digital stories by using electronic equipment procured under the project (plasma, cameras, recorders etc.).

Librarians, together with the creators of digital stories, have also organized public debates in order to help create common cultural reflections in each library and strengthen the cultural "agora" emulation space. After organizing free-of-charge workshops, the digital storytelling with dramatic potential created by users has become the inspiration for an original theater show - In Your Own Words - which was presented in all 4 centers and which is currently included in the permanent repertoire of the REPLIKA Cultural Association. During the Cultural Agora project, a common portal on cultural diversity and identity in Romania was created, the project focusing on the specifics and the added value of the cultural heritage of minorities.

The participants to this project benefited from exposure to a professional working environment, access to international expertise and consulting, quality networking, access to technology, innovation and creativity, producing their own digital stories and media visibility through a multitude of channels and professional communication tools. Through Digital Storytelling, participants - library users and community members - have been encouraged to express and share their own creative ideas, write scenarios, edit photos, record and mix sounds by using the logistics available in the project. In the context of implementing the Agora Cultural activities, each of the 4 participating county libraries was equipped with five sets of laptops, scanners, recorders, cameras, as well as TV plasma needed to disseminate digital stories through permanent exhibitions.

From the perspective of the historical and symbolic value of the remembered cultural heritage, the images that illustrate the digital stories (in scanned or photographed format) also add value to participants' testimonials and stories, whether we are talking about vintage photographs, historical, cultural or family, icons, jewelry, furniture, musical objects, or any other architectural, clothing or even personal objects that are brought to the attention of the public at large. 


\section{Discussion and conclusions}

By creating this audio-visual cultural repertoire of original digital stories in the public library, but especially by accessing it through permanent exhibitions, the library fulfills a mission which goes beyond the times, beyond the sentimental history of that geographic space and the local or personal legends. In this way, the library becomes the manager of a collective cultural treasure, meant to reveal to the next generations, the importance of local memory for the harmonious development of the community, while observing its history and authentic cultural values.

Thanks to this project, the library - as a main catalyst and message-bearer for the public at large became an important vector in the exchange of cultural knowledge, with significant benefits for the consumers of culture and cultural education in general. By creating and disseminating collections of digital stories during the project deployment, the libraries involved have contributed significantly to the growing appetite for culture and the involvement of community members in the urban and rural socio-cultural life, by stimulating creativity, individual expression and personal skills development.

By creating a space for cultural emulation in the public library, the Cultural Agora project generated a massive cultural movement of attracting young people to culture, arts, community participation and cultural inspiration activities.

The involvement in the Cultural Agora project has generated a tremendous transformation of the participants, in terms of their acquiring knowledge in the field of audio-video, and the crystallization of collaboration relationship based on common values and the natural desire to share stories and experiences.

Via the Digital Storytelling workshops organized, the libraries involved have become authentic recipients of creation and learning. The value of this course is given by the original digital archive of stories that constitutes an extremely valuable patrimony of inestimable values, beliefs, habits and personal experiences.

In addition, participation in the Cultural Agora project generated a whole movement of recovery stories on cultural diversity. As a result of participating in the Agora Cultural workshops, library services users understood how important it is to become aware of their identity and ethnic specificity. All those who were part of the story: storytellers, trainers, mentors or simple spectators, overcame their fears, exceeded their limits and chose to be honest with themselves and with the others. Thus, the Agora story gallery has become a priceless collection of testimonies and experiences about culture and diversity.

The main change occurred at the level of perception. Thanks to the Cultural Agora project, several disadvantaged audiences in terms of social, geographical or ethnic affiliation to one group or another, benefited from access to technology, modern equipment, training and quality networking.

Moreover, via the project activities, an important capital of sympathy for stories and for cultural diversity was generated; the public's perception on cultural occupations was improved; the library as an opinion maker and facilitator of learning was promoted; and the offer of cultural institutions was improved due to the creation of a modern Digital Storytelling service for the community.

Cultural Agora has placed the Romanian cultural capital, quality education and innovative library services in the center of its concerns, in order to encourage the community members to participate actively to cultural life.

Currently, several cultural and artistic institutions, libraries and NGOs involved in culture and minorities' issues, media representatives and local decision-makers as well as central and local public institutions are among the partners and supporters of the Cultural Agora project.

CulturalAgora@Your Library project has demonstrated that Digital Storytelling can bring about 
favourable changes in the community, both in terms of acquiring new knowledge in the field of creative arts and technology, as well as in mobilizing different ethnic communities in the preservation of intangible cultural heritage.

On the other hand, the Cultural Agora experience has revealed to everyone involved the importance of collaborating and exchanging information, by using the public library infrastructure. It was an emulation of extremely beneficial ideas: we discovered incredible life stories and interacted with really surprising people. This project has shown us all that, regardless of social status or membership in one community or another, people have a particular appetite to share stories.

With the support of participating libraries, the Cultural Agora community has become a real treasure of humanity and of the critical thinking of several generations, an invaluable territory for the dynamic transfer of information, where community members have been successively the storytellers, the actors and the spectators of a diversity show, created and re-created in libraries just like in an authentic antique Agora. 